\title{
Distribution of cortical neurons projecting to the superior colliculus in macaque monkeys
}

This article was published in the following Dove Press journal:

Eye and Brain

23 September 2014

Number of times this article has been viewed

\section{Christina M Cerkevich' \\ David C Lyon ${ }^{2}$ \\ Pooja Balaram ${ }^{3}$ \\ Jon $\mathrm{H} \mathrm{Kaas}^{3}$}

'Department of Neurobiology, University of Pittsburgh School of Medicine, Systems Neuroscience Institute, Pittsburgh, PA, USA; ${ }^{2}$ Department of Anatomy and Neurobiology, University of California, Irvine, CA, USA; ${ }^{3}$ Department of Psychology, Vanderbilt University, Nashville, TN, USA
Correspondence: Jon H Kaas Department of Psychology, Vanderbilt University, 30I David K Wilson Hall,

III 2 Ist Avenue South, Nashville,

TN 37203, USA

Tel + I 6153226029 (office);

+I 615322 749I (laboratory)

Fax + I 6153438449

Email jon.h.kaas@vanderbilt.edu

\begin{abstract}
To better reveal the pattern of corticotectal projections to the superficial layers of the superior colliculus (SC), we made a total of ten retrograde tracer injections into the SC of three macaque monkeys (Macaca mulatta). The majority of these injections were in the superficial layers of the $\mathrm{SC}$, which process visual information. To isolate inputs to the purely visual layers in the superficial SC from those inputs to the motor and multisensory layers deeper in the SC, two injections were placed to include the intermediate and deep layers of the SC. In another case, an injection was placed in the medial pulvinar, a nucleus not known to be strongly connected with visual cortex, to identify possible projections from tracer spread past the lateral boundary of the SC. Four conclusions are supported by the results: 1) all early visual areas of cortex, including V1, V2, V3, and the middle temporal area, project to the superficial layers of the SC; 2) with the possible exception of the frontal eye field, few areas of cortex outside of the early visual areas project to the superficial SC, although many do, however, project to the intermediate and deep layers of the $\mathrm{SC} ; 3$ ) roughly matching retinotopy is conserved in the projections of visual areas to the SC; and 4) the projections from different visual areas are similarly dense, although projections from early visual areas appear somewhat denser than those of higher order visual areas in macaque cortex.
\end{abstract}

Keywords: visual cortex, superior colliculus, frontal eye field, posterior parietal cortex, visual system

\section{Introduction}

The superior colliculus (SC) is an important visual structure involved in maintaining fixation, generating saccadic eye movements, and directing the head and eyes toward objects of interest. ${ }^{1,2}$ The SC also has a role in generating defensive movements of the head and limbs to protect against injuries. ${ }^{3,4}$ Afferent projections to the SC include those directly from the retina, as well as those from, especially, visual and visuomotor areas of cortex..$^{5-9}$ Efferent projections include those to motor and premotor neurons of the brainstem that are involved in head and eye movements, parts of the visual pulvinar that provide a non-geniculate source of visual input to the cortex, and the koniocellular layers of the dorsal lateral geniculate nucleus that relay visual inputs to V1 and several other visual areas. ${ }^{5,6,8}$ The SC is a well-laminated structure, with different layers having different inputs and outputs to cortical and subcortical areas. In general, visual areas project to the superficial layers, while visuomotor areas project to intermediate and deeper layers of the SC.,9-12

In macaque monkeys, cortical projections to the SC have been demonstrated by placing injections of anterograde tracers into various locations within visual and 
nonvisual areas of cortex, ${ }^{7,12,13}$ or by injections of retrogradely transported tracers into the SC in order to label neurons in cortex. ${ }^{14-18}$ Studies based on injections in the SC allow the magnitudes and visuotopic pattern of projections of different cortical areas to be directly compared, as corticotectal neurons in a number of areas are labeled by each injection in the SC. There have been two comprehensive studies based on retrograde $\mathrm{SC}$ injections. In the earlier study, Fries ${ }^{15}$ placed typically large, single injections of horseradish peroxidase into the SC of macaque monkeys and located labeled neurons in brain sections cut in the horizontal plane. In a similar manner, Lock et al ${ }^{17}$ injected a single fluorescent tracer, fast blue (FB) or diamidino yellow (DY), into the SC and located labeled cortical neurons in brain sections cut in the parasagittal plane. Both studies illustrated patterns of corticotectal neuron distributions on a lateral view of the cerebral hemisphere ${ }^{15}$ or of an unfolded cerebral hemisphere simulation ${ }^{17}$ that exposed cortex within the sulci. The results of the studies are extremely valuable, in that they demonstrated projections from a number of occipital visual areas with superficial SC injections and frontal and parietal visuomotor areas with deeper SC injections.

In the present study, we sought to extend and complement these earlier studies by injecting up to four of a selection of five distinguishable retrograde tracers into separate retinotopic locations in the SC of three macaque monkeys. To avoid the possibility of contaminating cortex with these injections, we aspirated part of one cerebral hemisphere so that the contralateral SC could be visualized and injected. Subsequently, we manually unfolded and flattened the cortex of the hemisphere containing labeled neurons so that the flattened cortex could be cut parallel to the pial surface. These methods avoided the contamination of the cortex with tracers from SC injections and assured that all labeled neurons in the cortex possessed subcortical projections.

The use of multiple tracers in the SC allowed distributions of neurons labeled from different locations in the cortex to be directly compared in the same hemisphere. In addition, labeled neurons could be most accurately plotted in a surface view of the cortex from brain sections cut parallel to the flattened surface. ${ }^{19}$ Sections processed for myelin or cytochrome oxidase (CO) were used to help define cortical areas.

\section{Materials and methods}

Three adult macaque monkeys (Macaca mulatta) were used in this study. The experimental procedures were approved by the Vanderbilt University Animal Care and Use Committee and adhered to National Institutes of Health guidelines. Each animal was anesthetized with an initial injection of ketamine hydrochloride (10-35 mg/kg intramuscularly) and then intubated. Survival surgeries were performed under $2 \%$ isoflurane anesthesia using aseptic conditions.

\section{Surgical procedures and tracer injections}

For cases 1 and 2, the skull was exposed and a craniotomy was performed to expose the dorsolateral parietal cortex of the left hemisphere. A portion of cortex between the intraparietal sulcus (IPS) and lunate sulcus was aspirated to provide access to the contralateral SC. Injections of up to four fluorescent tracers were placed in the right SC with a Hamilton syringe mounted on a micromanipulator. In attempting to inject the superficial layers of the $\mathrm{SC}, 0.2 \mu \mathrm{L}$ of the following tracers were injected across the SC: FB (3\% in distilled water) (Molecular Probes ${ }^{\circledR}$; Life Technologies, Carlsbad, CA, USA); Fluororuby ([FR] 10\% in distilled water) (Molecular Probes); fluoro-emerald ([FE] $10 \%$ in distilled water) (Molecular Probes); DY ( $2 \%$ in $0.1 \mathrm{M}$ phosphate buffer) (Sigma-Aldrich, St Louis, MO, USA); and cholera toxin subunit B conjugated to fluorescein isothiocyanate green ([BFITC] 5\% in distilled water) (Sigma-Aldrich). In case 3 , no aspiration was performed; instead, two injections of FR were placed in the left SC using a Hamilton syringe located at stereotaxic coordinates above the SC that were informed by previous magnetic resonance imaging (MRI) performed in this animal. After the injections were placed, the region of the cortical lesion was covered with gel foam and the experimental cortex with a contact lens or gel film. The skull was closed with a cap of dental cement and the skin was sutured. The monkeys were then given analgesics and precautionary antibiotics to avoid inflammation and infection and were carefully monitored during recovery from anesthesia.

\section{Histology}

After a 10-14 day survival period to allow for the axonal transport of tracers and second set of unrelated mapping experiments, the animals were given a lethal dose of sodium pentobarbital and perfused through the heart with phosphatebuffered saline ([PBS] pH 7.4), followed by $2 \%$ paraformaldehyde in PBS, and then $2 \%$ paraformaldehyde with $10 \%$ sucrose in PBS. The brain was removed and the cortex separated from the brain stem and thalamus. The cortex was blocked and flattened as described in Lyon and $\mathrm{Kaas}^{20}$ and Stepniewska et $\mathrm{a}^{21}$ (Figure 1), held between two glass slides, and stored overnight in $30 \%$ sucrose at $4^{\circ} \mathrm{C}$. The brain stem and thalamus were blocked and also stored in $30 \%$ sucrose at $4^{\circ} \mathrm{C}$. The cortex was cut parallel to the surface at a thickness of $40-50 \mu \mathrm{m}$ on a freezing microtome. Depending on the tracers used, and four alternating series were mounted unstained for fluorescence 

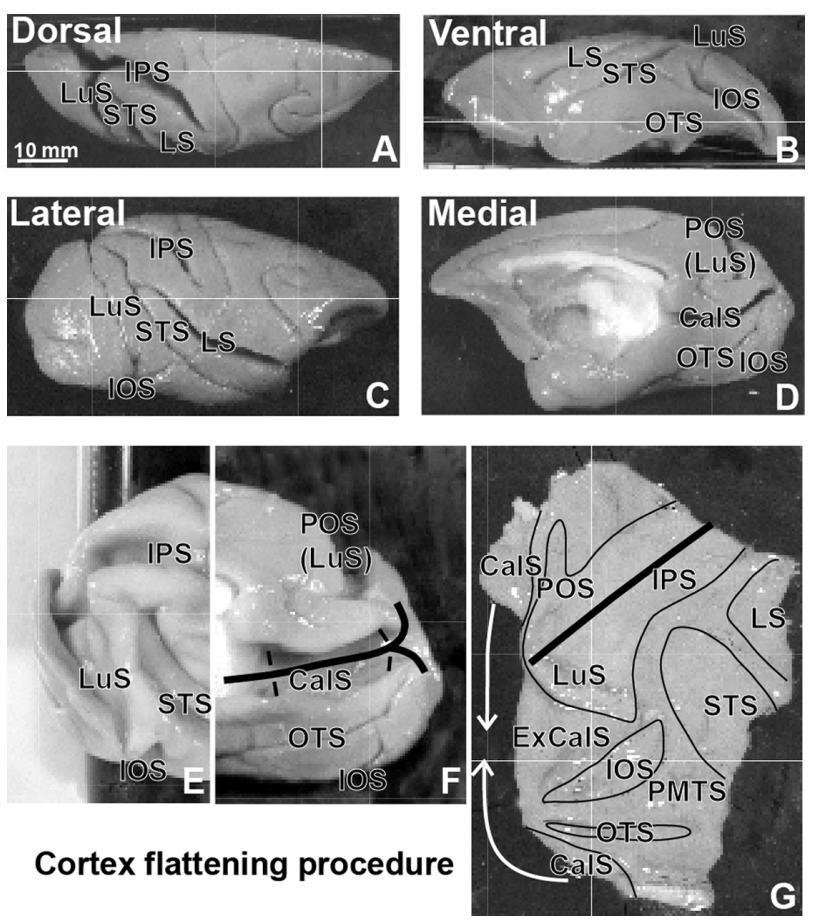

Cortex flattening procedure

Figure I Cortex flattening procedure.

Notes: (A-D) Dorsal, ventral, lateral, and medial views of the right hemisphere with marked sulci. (E-G) The procedure used to flatten the visual cortex of the cauda part of the hemisphere. In ( $\mathbf{F}$ and $\mathbf{G}$ ), thick black lines mark cuts along the calcarine sulcus on the medial wall and the IPS on the dorsal aspect of the hemisphere. In (G), thin black lines mark contours of opened sulci. Copyright (C) 2005. Oxford University Press. Adapted from Stepniewska I, Collins CE, Kaas JH. Reappraisal of DL/V4 boundaries based on connectivity patterns of dorsolateral visual cortex in macaques. Cereb Cortex. 2005; 15(6):809-822 by permission of Oxford University Press. ${ }^{21}$

Abbreviations: CalS, calcarine sulcus; ExCalS, external CalS; IOS, inferior occipital sulcus; IPS, intraparietal sulcus; LS, lateral sulcus; LuS, lunate sulcus; OTS, occipitotemporal sulcus; PMTS, posteromedial temporal sulcus; POS, parietooccipital sulcus; STS, superior temporal sulcus.

microscopy, processed for myelin ${ }^{22}$ or for $\mathrm{CO}^{23}$ The brainstem was cut coronally on a freezing microtome at a thickness of $40-50 \mu \mathrm{m}$. As with the cortex, a series containing every fourth section was mounted for fluorescence microscopy. Additional series were processed for immunohistochemistry, stained for $\mathrm{CO}$ or Nissl substance, or reacted for acetylcholinesterase $(\mathrm{AChE}),{ }^{24}$ to reveal areal and laminar boundaries in the SC.

\section{Data analysis}

Core zones of the injections in the brainstem were outlined, and cortical neurons labeled with fluorescent tracers were plotted using a fluorescence Leitz microscope coupled to a Neurolucida ${ }^{\mathrm{TM}}$ system (Leica Microsystems, Wetzlar, Germany) or a Leitz microscope coupled to an X, Y encoder and a Macintosh G3 computer (Apple Inc, Cupertino, CA, USA) running IGOR Pro ${ }^{\mathrm{TM}}$ software (WaveMetrics, Inc, Portland, OR, USA). Blood vessels and other landmarks were marked on the plots for alignment with sections stained for $\mathrm{CO}$, Nissl, or AChE. Injection cores were outlined and aligned with adjacent sections stained for CO, Nissl, or AChE to determine the depth of the injections in relation to the layers of the SC. Measurements of the width and depth of each injection in relation to the SC layers were made on coronal sections through the midbrain and then used to reconstruct the injections sites across both the rostral-caudal and medial-lateral extent of the SC, as depicted in the dorsal views shown in the left hand column of Figure 2. The retinotopic map was estimated from previously published maps of retinotopy in the $\mathrm{SC},{ }^{1}$ and placed on dorsal reconstructions of injection sites based on SC landmarks. To locate labeled neurons in relation to areal boundaries in the visual cortex, plotted cortical sections were aligned with sections stained for $\mathrm{CO}$ or myelinated fibers using blood vessels and other major landmarks in each area. Borders between V1 and V2, $\mathrm{V} 2$ and V3, and surrounding middle temporal area (MT) were also revealed by $\mathrm{CO}$ and fiber staining and marked on aligned plots. The areal borders indicated in our figures were consistent with measurements from previous studies (MT from Weller and Kaas; ${ }^{25}$ V2 from Olavarria and Van Essen; ${ }^{26}$ V3 from Lyon and $\mathrm{Kaas}^{20}$ ). The location of the cortical representation of the horizontal meridian (HM) was estimated based on cortical landmarks. Images of the reconstructions were created with Canvas 8 (ACD Systems International Inc, Seattle, WA, USA) and Illustrator CS2 ${ }^{\mathrm{TM}}$ (Adobe Systems Incorporated, San Jose, CA, USA). Illustrator's count function was used to determine the total number of cells labeled by each tracer injection, as well as the number of cells labeled by each tracer in individual cortical areas. Each area's proportion of the total projection was analyzed by determining the percentage of total labeled cells contained within the area compared to the total labeled cells across the cortex (Tables 1 and 2). Digital photomicrographs of sections were acquired using a Nikon DXM1200 (Nikon Instruments, Melville, NY, USA) camera mounted on a Nikon E800 microscope (Nikon Instruments). Images were then adjusted for contrast, saturation, and brightness with Adobe Photoshop CS2 ${ }^{\text {TM }}$ (Adobe Systems Incorporated).

\section{Results}

The projections of visual cortex to the superficial SC were determined from ten injections in three macaque monkeys. In two cases, injections of multiple tracers into a single $\mathrm{SC}$ were used to show any topography in the corticotectal projections. The more traditional method of making a large injection of a single tracer to fill the SC was performed in the third case. The distributions of labeled cells resulting from these injections were plotted in flattened cortex in order 
to demonstrate the areal and retinotopic patterns of these projections. The manual flattening procedure used in these cases allowed for comparisons of the distributions of labeled neurons within the boundaries of cortical areas, as identified by architectural stains, without the distortions inherent in reconstructions of surface views based on serial coronal or sagittal brain sections. Thus, this technique allowed us to compare the areal magnitudes of projections to the SC by identifying the total number of labeled cells in each area and comparing them with the total number of labeled cells across the cortex for each tracer injection. This technique did lead to a loss of precise information about the layers of the cortex
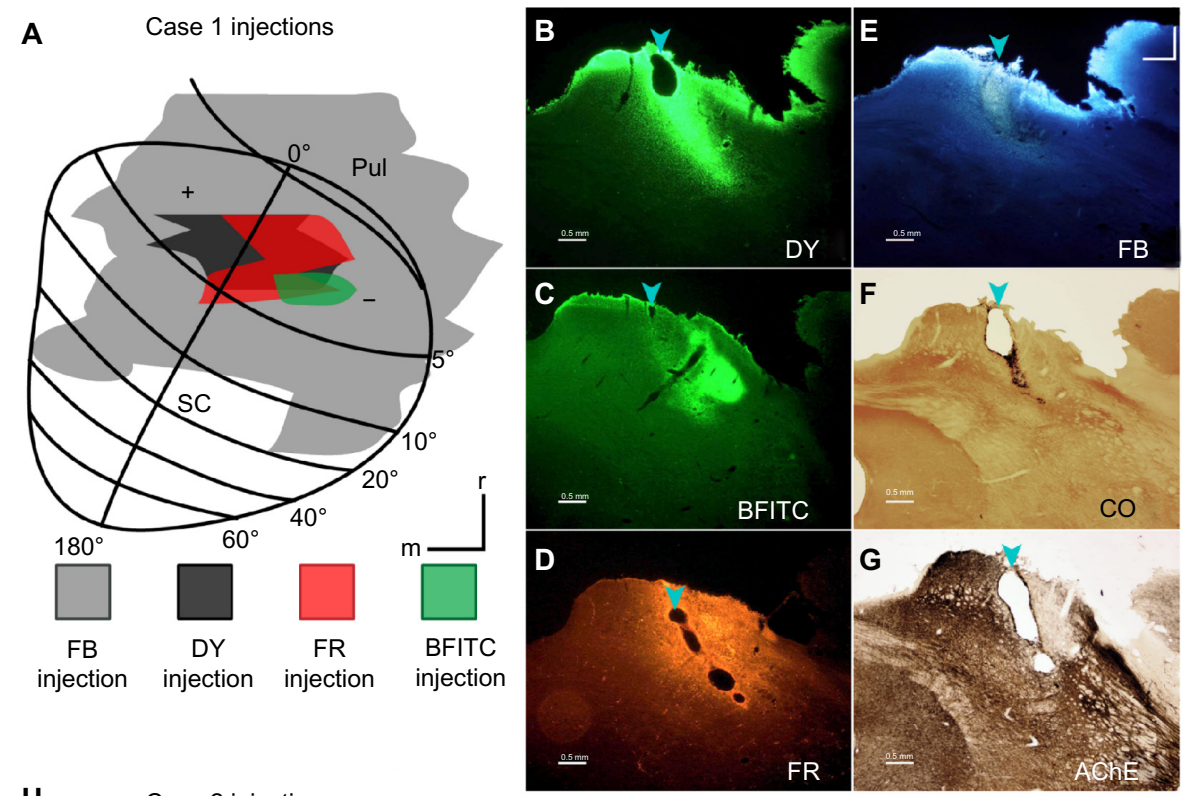

H Case 2 injections
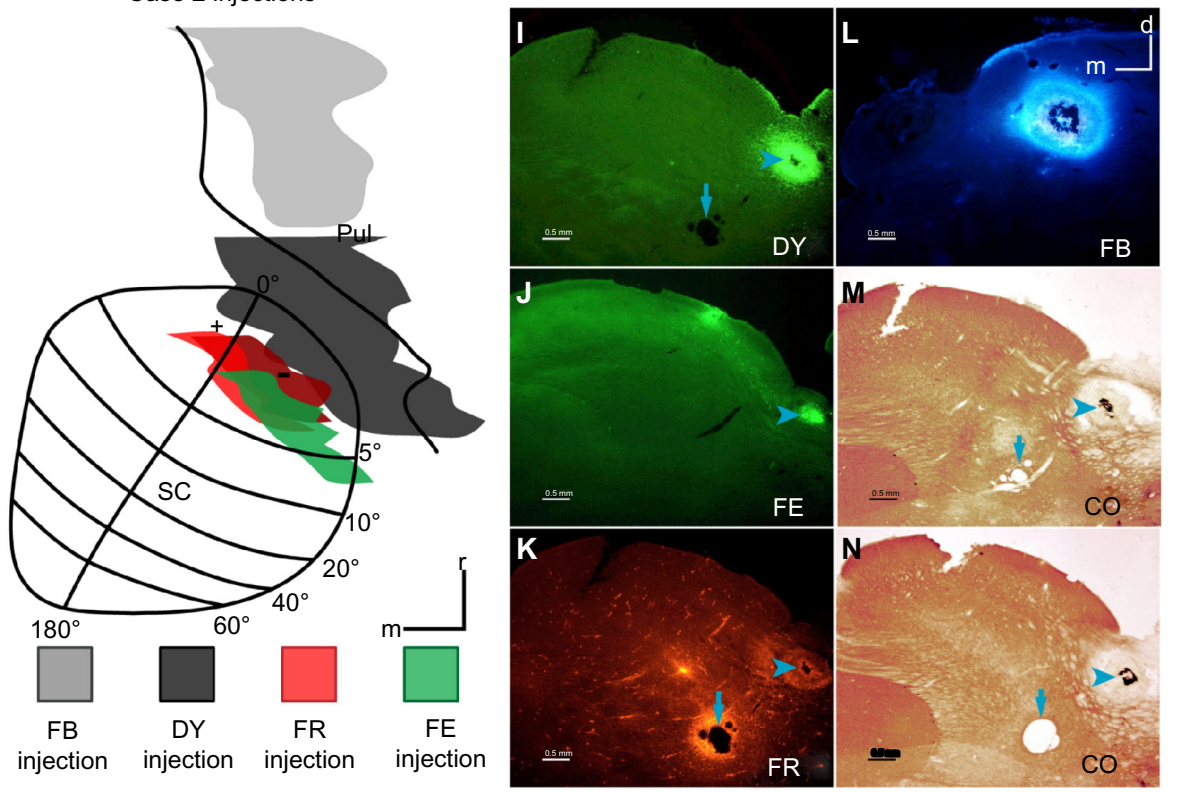

Figure 2 Injections in cases $I$ and 2.

Notes: $(\mathbf{A}$ and $\mathbf{H})$ Top-down views of the reconstructed case I and case 2 injection sites in the SC. A depiction of the retinotopy of the SC was based on the maps of Kaas and Huerta' is superimposed over the SC. Central vision is represented rostrolaterally: + denotes the upper field, - denotes the lower field. Left is medial ( $m$ ), up is rostral ( $r$ ). (B-E) Photomicrographs of the case I injection sites in coronal sections through the SC and pulvinar. Injection cores can be distinguished from the surrounding tissue as a brightly fluorescing region often surrounding a small damaged region caused by the injection of each tracer. Sections were chosen to show the largest part of the injection site. (F and $\mathbf{G})$ $\mathrm{CO}$ and $\mathrm{AChE}$ sections adjacent to the pictured injection sites in case I. Here, the location of injection cores is distinguished by the region damaged by the tracer injection. Darts indicate the location of the DY injection core across sections. (I-L) Photomicrographs of the case 2 injection sites in coronal sections through the SC and pulvinar. ( $\mathbf{M}$ and $\mathbf{N}$ ) $\mathrm{CO}$ sections adjacent to the injection sites in case 2. Darts indicate the location of the DY injection core across sections, while arrows mark the deeper focus of the FR injection. Scale bar is $0.5 \mathrm{~mm}$ for all photomicrographs. (A) and (H) Copyright (C) 1988. John Wiley \& Sons, Inc. This material is reproduced from Kaas J, Huerta M. The subcortical visual system of primates. In: Steklis H, editor. Comparative primate biology. New York: Alan R. Liss, Inc; 1988;4:327-39I with permission of John Wiley \& Sons, Inc.'

Abbreviations: AchE, acetylcholinesterase; BFITC, cholera toxin subunit B, conjugated to BFITC; CO, cytochrome oxidase; DY, diamidino yellow; FB, fast blue; FR, Fluororuby; Pul, pulvinar; SC, superior colliculus; FE, fluoro-emerald. 
that project to the $\mathrm{SC}$; however, the projections from most of the cortex to the SC are known to come from pyramidal cells in layer V, while layer VI of the primary visual cortex projects subcortically to both the thalamus and SC. ${ }^{15,16,18}$ This technique also allowed us to compare the magnitude of each area's projection to the $\mathrm{SC}$.

\section{Case I visual cortex}

In case 1 , four fluorescent tracers (DY, FR, BFITC, and FB) were placed in the rostral part of the SC that represents central vision (Figure 2A), across its mediolateral extent, in order to show any topography in the projections from cortex. The DY and FR injection cores partially overlapped, allowing for uptake of either or both tracers from this zone of overlap. The core of the FB injection was largely in the rostral SC, but also extended into the inferior pulvinar of the thalamus, which is known to project to early visual areas. ${ }^{27}$ While FB damaged the SC where it was injected, its effect on the uptake of the other tracers should be relatively limited, ${ }^{28}$ and all four tracers clearly labeled neurons in the visual cortex.

The DY injection (Figure 2A, black) was centered on the representation of the $\mathrm{HM}$, and it included both the upper and lower field representations. The injection core (Figure 2B) involved the superficial layers (stratum zonale [SZ], stratum griseum superficiale [SGS], and stratum opticum [SO]) and some of the upper intermediate layer, the stratum griseum intermedium (SGI), of the colliculus. Cells labeled by this injection (Figure 3) were distributed on both sides of the $\mathrm{HM}$ in V1, V2, V3, the dorsolateral area (DL or V4), and MT, although they were more densely distributed in the upper field. Cortical regions of the dorsomedial area (DM), the medial superior temporal area, and the fundus of the superior temporal sulcus also contained labeled cells, though the borders of these areas were largely based on locations determined in previous experimental studies..$^{20,21,24,25}$ DY cells were also found around the tip of the superior temporal sulcus

Table I Percent of total labeled neurons in early visual areas in case I

\begin{tabular}{llllll}
\hline & $\begin{array}{l}\text { Total } \\
\text { number } \\
\text { of labeled } \\
\text { neurons }\end{array}$ & $\begin{array}{l}\text { Percent } \\
\text { of labeled } \\
\text { neurons } \\
\text { in VI }\end{array}$ & $\begin{array}{l}\text { Percent } \\
\text { of labeled } \\
\text { neurons } \\
\text { in V2 }\end{array}$ & $\begin{array}{l}\text { Percent } \\
\text { of labeled } \\
\text { neurons } \\
\text { in MT }\end{array}$ & $\begin{array}{l}\text { Percent } \\
\text { of labeled } \\
\text { neurons } \\
\text { in other } \\
\text { areas }\end{array}$ \\
\hline DY & 9,794 & 39.82 & 10.95 & 5.00 & 44.23 \\
FR & 4,364 & 54.65 & 8.78 & 5.64 & 30.93 \\
BFITC & 91 & 4.40 & 17.58 & 16.48 & 61.54 \\
FB & I4,42I & 45.57 & 17.42 & 3.38 & 33.63 \\
\hline
\end{tabular}

Abbreviations: BFITC, cholera toxin subunit b, conjugated to BFITC; DY diamidino yellow; FB, fast blue; FR, Fluororuby; MT, middle temporal area.
Table 2 Percent of total labeled neurons in early visual areas in case 2

\begin{tabular}{llllll}
\hline $\begin{array}{l}\text { Total } \\
\text { number } \\
\text { of labeled } \\
\text { neurons }\end{array}$ & $\begin{array}{l}\text { Percent } \\
\text { of labeled } \\
\text { neurons } \\
\text { in V }\end{array}$ & $\begin{array}{l}\text { Percent } \\
\text { of labeled } \\
\text { neurons } \\
\text { in V2 }\end{array}$ & $\begin{array}{l}\text { Percent } \\
\text { of labeled } \\
\text { neurons } \\
\text { in MT }\end{array}$ & $\begin{array}{l}\text { Percent } \\
\text { of labeled } \\
\text { neurons in } \\
\text { other areas }\end{array}$ \\
\hline FE & 9,794 & 39.37 & 26.28 & 4.08 & 30.27 \\
FR & 4,364 & 12.28 & 3.42 & 4.43 & 79.87 \\
DY & 91 & 40.89 & 10.24 & 4.89 & 43.98 \\
FB $\quad$ I4,42I & 0.05 & - & 0.09 & 99.86 \\
\hline
\end{tabular}

Abbreviations: DY, diamidino yellow; $F B$, fast blue; FE, fluoro-emerald; $F R$, Fluororuby; MT, middle temporal area.

(STS). Labeled cells were sparsely distributed in the inferior temporal cortex (IT). No labeled cells were detected around the IPS, including the region of the lateral intraparietal area (LIP), suggesting that there was no tracer uptake from the intermediate layers of the SC. The locations of DY-filled neurons were consistent with the retinotopic location of the injection. The strongest projection revealed by this injection was from V1, although MT also had a high percentage of labeled cells, given its relatively small size compared to V1 (Table 1).

The FR injection (Figure 2A, red) was largely in the lower field representation, with some spread across the HM into the representation of the upper visual field. Much like DY, this injection may have spread to the upper part of the SGI (Figure 2D). The cores of the FR and DY injections overlapped, especially near the representation of the HM. FR-filled neurons (Figure 4) lie in both the upper and lower field representations, and were concentrated in V1, V2, V3, and MT. The distribution of backfilled neurons was sparser near the tip of the STS and IT compared to those seen with the DY injection. Again, the IPS was devoid of cells, suggesting that axons reaching into the SGI did not take up tracer. Just like the DY injection, the locations of labeled neurons in early visual areas matched the retinotopic location of the injection. As expected, the distribution of labeled neurons shifted medially, in V1, compared to the neurons from the more medial SC injection (Figure 3). Most of the labeled neurons revealed by the FR were in V1, but V2 and MT also had high numbers of labeled neurons (Table 1).

BFITC was a small injection (Figure 2A, green), confined to the lower visual field, that largely occupied the lower SZ, SGS, and upper half of the SO (Figure 2C), but did not fill the full extent of the superficial layers. While only a few labeled cells in visual cortex were apparent, their distribution in early visual areas did match that revealed by the other injections in this case. No neurons filled with BFITC were found in IT, the STS, or near the IPS. Labeled cells were confined to the 
lower field representation of central vision in V1, V2, V3, DL, and MT. While most of the cells labeled by this injection were outside of V1, V2, and MT (Table 1), the magnitudes of projections from these areas was revealing. Few BFITC cells were in V1 (Table 1), perhaps because the injection did not include enough of the SZ and the upper SGS, the SC layers most likely to receive inputs from $\mathrm{V} 1,^{11,12}$ to indicate the dense V1 to superficial SC projection revealed by our other injections. V2 and MT contained more cells (Table 1), as expected from this injection into the deeper part of the

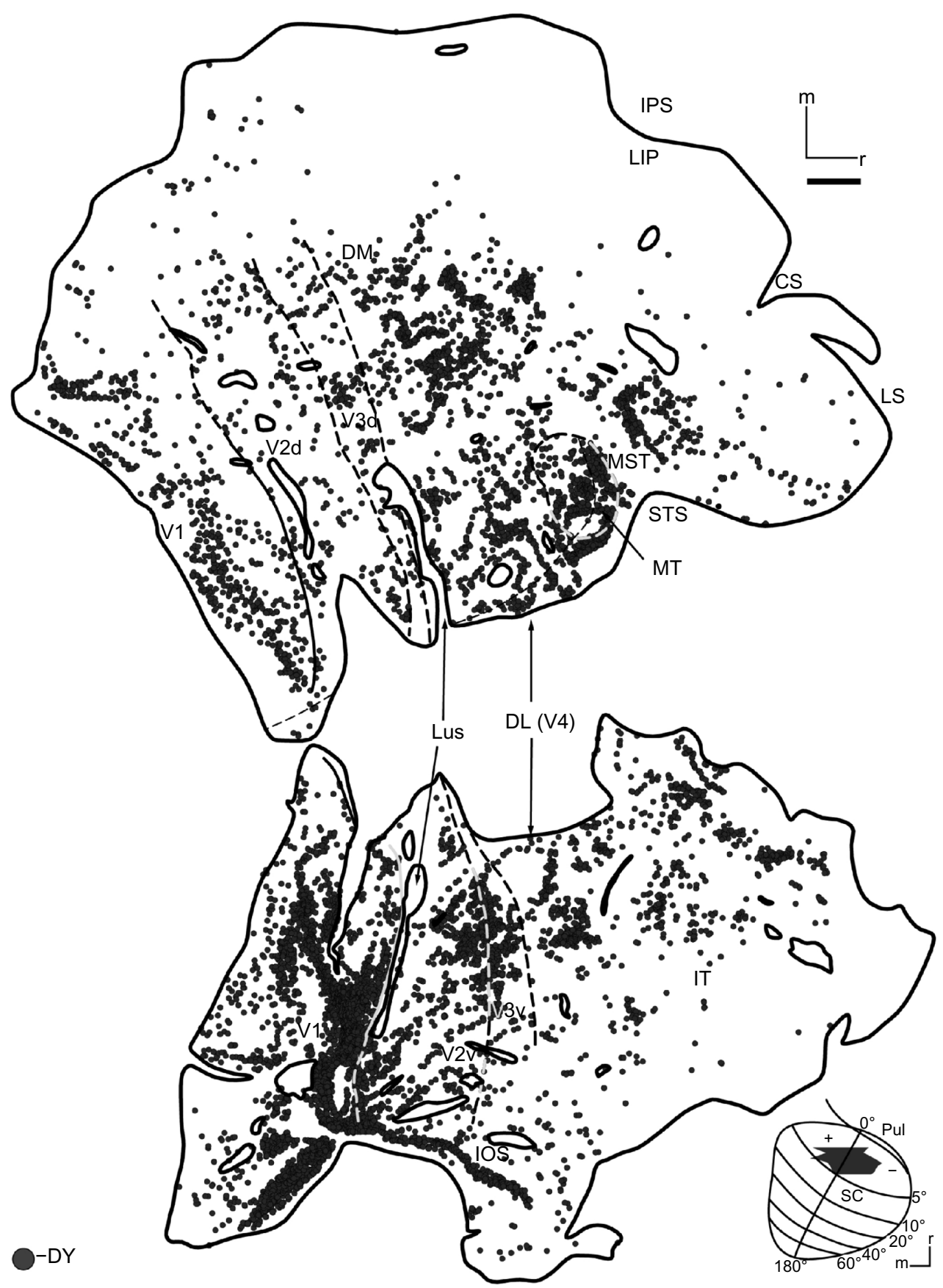

Figure 3 DY-labeled cells in case I.

Notes: Black circles indicate the distribution of DY-labeled cells through the right visual cortex of case I. Areal boundaries were determined from adjacent sections stained for cytochrome oxidase and myelin. Thin black lines are borders determined from anatomical sections. Dashed lines indicate borders that were determined from both anatomical sections and measurements. The finest dashed line is the horizontal meridian. Thick black lines denote tears and the edges of the block. In cortex, right is rostral, up is medial. Scale bar is $5 \mathrm{~mm}$.

Abbreviations: CS, central sulcus; DL, dorsolateral area; DM, dorsomedial area; DY, diamidino yellow; IOS, inferior occipital sulcus; IPS, intraparietal sulcus; IT, inferior temporal cortex; LIP, lateral intraparietal area; LS, lateral sulcus; LuS, lunate sulcus; MST, medial superior temporal area; MT, middle temporal area; Pul, pulvinar; SC, superior colliculus; STS, superior temporal sulcus; d, dorsal; v, ventral. 
superficial layers. ${ }^{11,12}$ The majority of cells (Table 1) backfilled by this slightly deeper, but still superficial injection were outside of $\mathrm{V} 1, \mathrm{~V} 2$, and $\mathrm{MT}$, in regions including $\mathrm{V} 3$ and $\mathrm{DL}$, again matching the pattern expected from injections at this depth in the SC.

The final tracer placed in case 1 was an injection of $\mathrm{FB}$ (Figure 2A, gray). It covered much of the rostral SC, filling the central vision representation. The extent of this injection in the SC was confined to the superficial layers (Figure 2E). The core zone of uptake extended into the inferior pulvinar, a thalamic division with known connections to early visual and IT cortex. ${ }^{27}$ This injection likely also included some nuclei of the pretectum, which receives projections from $\mathrm{V} 4,{ }^{29}$ parietal areas including LIP, ${ }^{30}$ and the frontal eye field (FEF). ${ }^{31}$ Neurons labeled by FB were densely distributed throughout most of visual cortex (Figure 5), especially in the lower field representation of V1 and into the STS, but showed sparse label around the IPS. There were many more cells labeled in IT, suggesting that IT is connected more strongly to the inferior pulvinar than it is to the superficial SC. Connections specific to either the SC or the pulvinar, however, could not be distinguished.

Because multiple fluorescent tracers were used, there were cells labeled by more than one tracer. The overlap in injection sites was restricted to retinotopically small regions of the SC (Figure 6). The location of double-labeled cells, consequently, provided information about the organization of these projections from the cortex to the SC. DY/ FR double-labeled cells (Figure 6C, light blue) lay mostly in the upper field representation and along the HM of early visual areas, matching the area of overlap in their injection sites. Neurons containing both FB and DY (Figure 6C, light green) were in the upper field of V1 and V2, also matching the location of the overlap of these injections. Only two FR/ FB double-labeled cells (Figure 6C, pink) were found in the upper field of V1.

\section{Case 2 visual cortex}

Three fluorescent tracers (FE, FR, and DY) were injected more laterally into the $\mathrm{SC}$ in case 2 , thus involving more of the lower visual field representation of the SC. All three injections involved the rostral half of the SC, which represents central vision. A fourth tracer, FB, was injected in the medial pulvinar. Because this nucleus receives projections from areas outside the early visual cortex, ${ }^{32}$ there was little expectation that labeled FB cells would overlap those labeled by the injections into the SC (Figure 2H).
Only the small FE injection was entirely confined to the superficial layers of the colliculus (Figure 2J). It was placed rostrolaterally in the SC in the representation of the lower visual field (Figure $2 \mathrm{H}$, green) and extended from central vision past $5^{\circ}$ of visual space. In the central vision representation, this injection avoided the HM. As it extended past $5^{\circ}$, this injection approached the vertical meridian (VM). V1, V2, V3, DM, DL, and MT all contained FE-filled cells (Figure 7, green). Only a small number of FE cells were found in the IT cortex, indicating few connections from this part of the cortex to the superficial SC. Almost no labeled neurons were found in areas lining the IPS, suggesting that this FE injection was confined to the superficial layers. Cells labeled by the FE injection were confined to the lower field representations in visual areas of cortex, matching the retinotopic location of the injection. Within V1, there were multiple clusters of FE-filled neurons. One cluster of FE-labeled neurons was located in the representation of the central lower field, between the VM and HM, matching the more central part of the injection. The second focus of FE cells in V1 was more peripheral, extending from central vision across $5^{\circ}$. As this injection abutted the lateral edge of the $\mathrm{SC}$, where the $\mathrm{VM}$ is represented, the location of this patch of labeled cells along the rostral edge of V1 was expected, since the VM is represented along the border of $\mathrm{V} 1$ with $\mathrm{V} 2$. The retinotopic distribution of labeled cells in V2 mirrored that of V1, with the distribution of FE cells extending from the more peripheral VM in caudal $\mathrm{V} 2$ toward the more central region between the VM and HM. Labeled cells in DM and DL were all confined to the lower field. In DM, these labeled cells were near the VM, while, in DL, FE neurons extended across a broad region of the lower field from the likely location of $5^{\circ}$ toward the HM. In MT, labeled cells followed the same retinotopic distribution seen in the other visual areas. Like the DY and FR labeled cells in case 1, the greatest number of labeled neurons was in V1, though many labeled neurons were in V2 and MT (Table 2).

There were two foci for the FR injection (Figure 2K). The smaller focus was in the central lower field representation, and extended slightly across the HM representation of the intermediate layers, SGI and stratum album intermedium (SAI) (Figure 2H, light red). The second focus was deep in the colliculus (Figure 2H, dark red, 2K). The FR injection that included the intermediate SC layers resulted in labeled cells more rostral to those labeled by the superficial FE injection (Figure 7, red). Those labeled in the early visual areas were distributed across the HM representation in central vision, as predicted by the retinotopic location of this injection. This injection labeled far more cells around the IPS than any of 


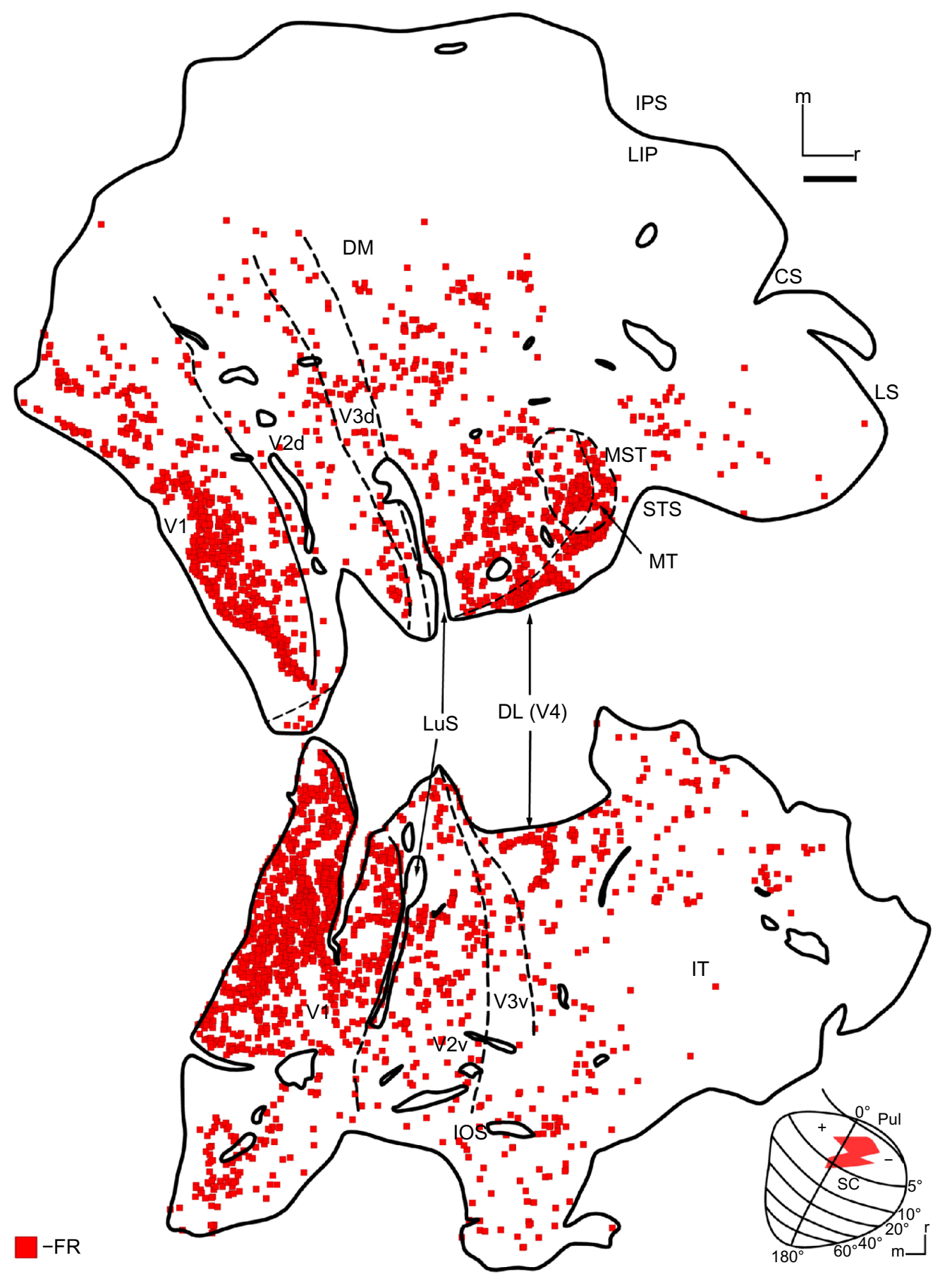

Figure 4 FR-labeled cells in case I.

Notes: Red squares indicate the distribution of FR-labeled cells through the right visual cortex of case I. In cortex, right is rostral, up is medial. Scale bar is 5 mm. Abbreviations: CS, central sulcus; DL, dorsolateral area; DM, dorsomedial area; FR, Fluororuby; IOS, inferior occipital sulcus; IPS, intraparietal sulcus; IT, inferior temporal cortex; LIP, lateral intraparietal area; LS, lateral sulcus; LuS, lunate sulcus; MST, medial superior temporal area; MT, middle temporal area; Pul, pulvinar; SC, superior colliculus; STS, superior temporal sulcus; d, dorsal; v, ventral.

those placed in the SC's superficial layers. These scattered cells in the posterior parietal cortex are likely the result of tracer spread into the intermediate layers. There were far fewer filled cells in the early visual areas; for example, V1 only contained only $12.3 \%$ of the total number of cells (Table 2 ).
The number of cells in MT was comparable to that revealed by other injections in both cases, suggesting that this injection did include at least the lower part of the superficial layers.

The DY injection (Figure 2H, black) was largely in the brachium of the SC, but the core did include superficial layers 


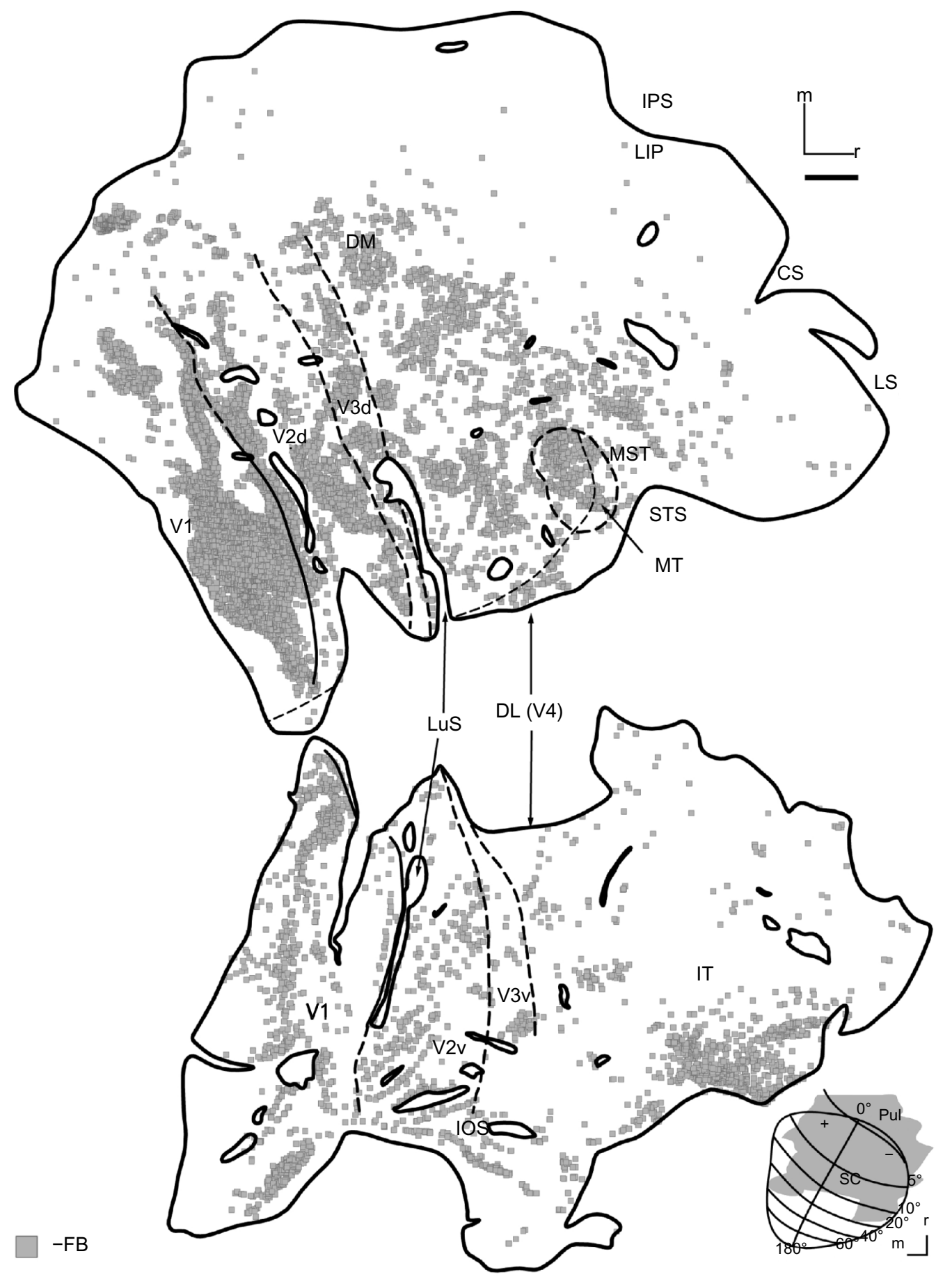

Figure 5 FB-labeled cells in case I.

Notes: Gray squares indicate the distribution of FB-labeled cells through the right visual cortex of case I. In cortex, right is rostral, up is medial. Scale bar is 5 mm. Abbreviations: CS, central sulcus; DL, dorsolateral area; DM, dorsomedial area; FB, fast blue; IOS, inferior occipital sulcus; IPS, intraparietal sulcus; IT, inferior temporal cortex; LIP, lateral intraparietal area; LS, lateral sulcus; LuS, lunate sulcus; MST, medial superior temporal area; MT, middle temporal area; Pul, pulvinar; SC, superior colliculus; STS, superior temporal sulcus; d, dorsal; v, ventral.

of the rostrolateral SC and the inferior pulvinar (Figure 2I). The zone of the injection in the SC was in the central lower field representation and extended slightly across the HM. DY-filled cells were scattered across the cortex (not shown). There was, however, a concentration of cells in the central vision representation near the HM, matching the part of the injection that was placed in the SC. Labeled areas again included V1, V2, V3, and MT. Much like the FE injection, the label in V1 appeared to be slightly heavier than other areas. MT label was also relatively dense in comparison to 


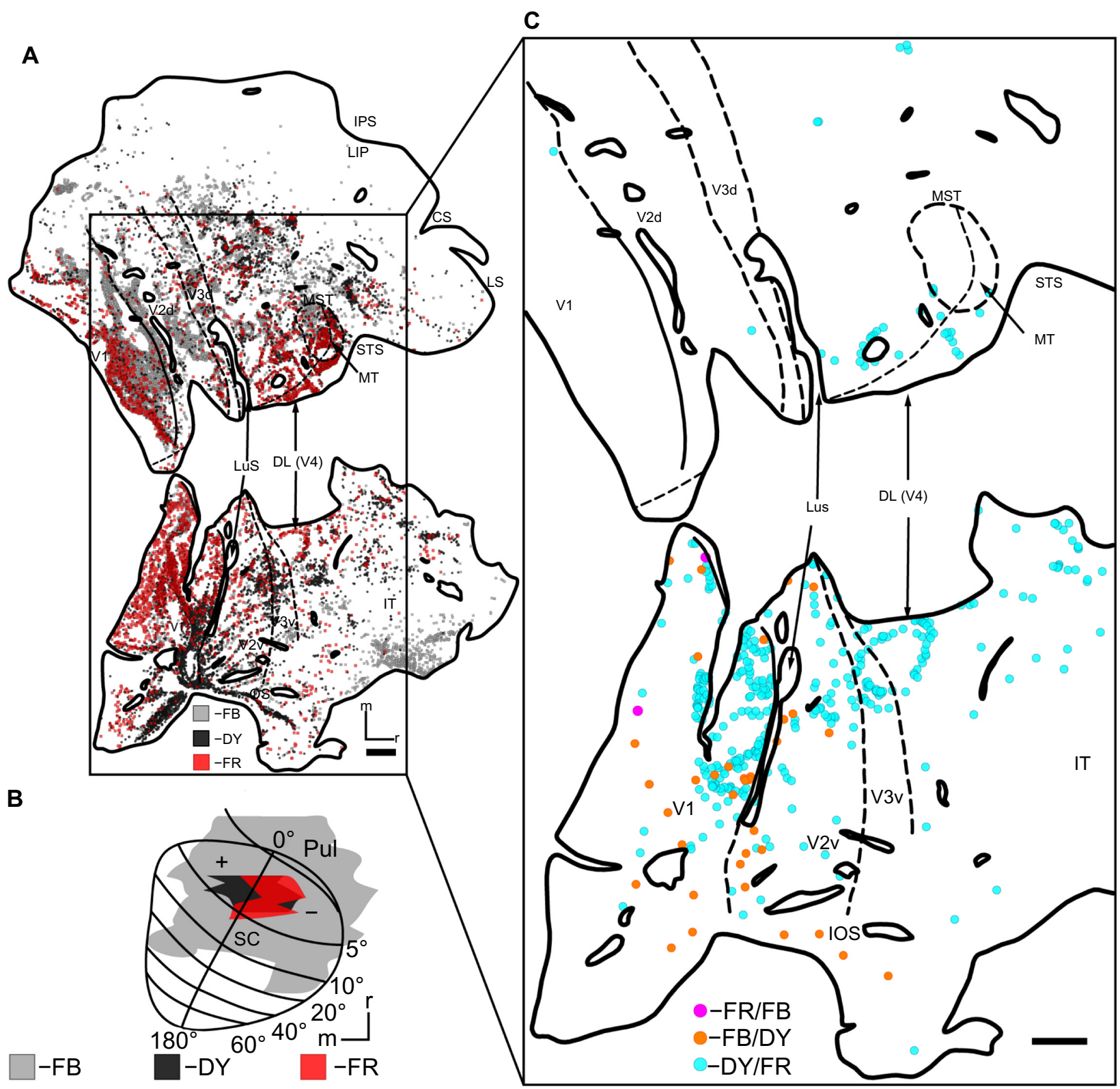

Figure 6 Double-labeled cells in case I.

Notes: (A) Distribution of single-labeled cells through the right visual cortex of case I. In cortex, right is rostral, up is medial. (B) Top-down view of the reconstructed case I injection sites in the SC. Left is medial, up is rostral. (C) Distribution of double-labeled cells through the right visual cortex of case I. Scale bar is 5 mm.

Abbreviations: CS, central sulcus; DL, dorsolateral area; DY, diamidino yellow; FB, fast blue; FR, Fluororuby; IOS, inferior occipital sulcus; IPS, intraparietal sulcus; IT, inferior temporal cortex; LIP, lateral intraparietal area; LS, lateral sulcus; LuS, lunate sulcus; MST, medial superior temporal area; MT, middle temporal area; Pul, pulvinar; SC, superior colliculus; STS, superior temporal sulcus; d, dorsal; v, ventral.

the other areas. IT projected densely to the injected region; however, because the injection was large and spread into the brachium and inferior pulvinar the exact target of these projections could not be distinguished.

An injection of FB was placed into the medial division of the pulvinar complex (Figure 2H, gray, and 2L). Previous studies showed that this part of the thalamus projects to IT cortex, areas in the STS, and other rostral areas of the brain. ${ }^{27,32}$ Unlike in the SC injections, $99.86 \%$ of cells were outside of early visual areas (Table 2). Most areas were almost completely devoid of FB-filled cells (Figure 7, gray), but many labeled cells were seen around the IPS and lateral sulcus. Furthermore, label in ventral IT was heavier than that resulting from the other injections in this case.

\section{Case 3 visual cortex}

In case 3 (not shown), two injections of FR covered all of the layers of the $\mathrm{SC}$, including the deep stratum griseum 


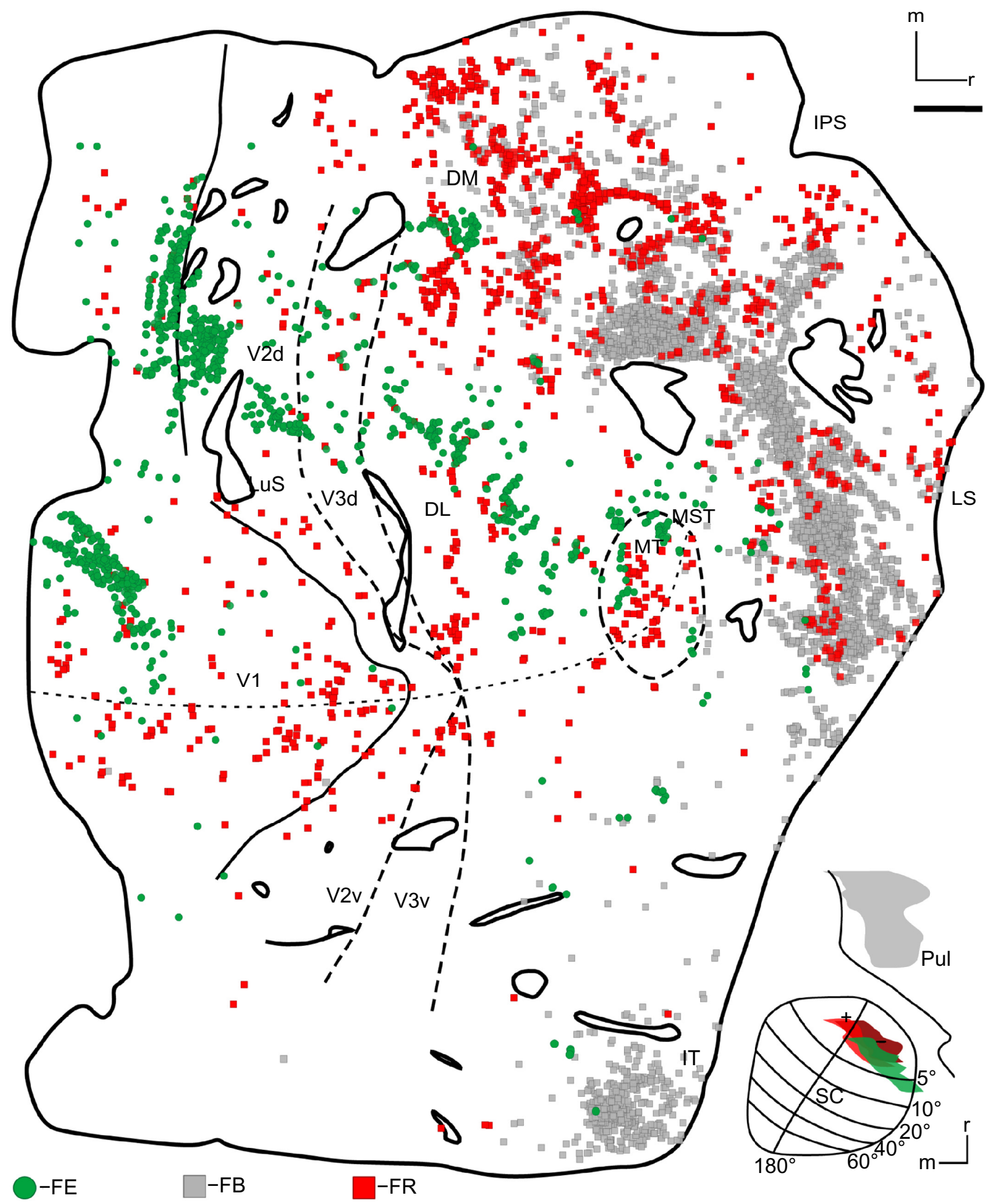

Figure 7 The distribution of cells through the right visual cortex of case 2.

Note: In cortex, right is rostral, up is medial. Scale bar is $5 \mathrm{~mm}$.

Abbreviations: DL, dorsolateral area; DM, dorsomedial area; FB, fast blue; FE, fluoro-emerald; FR, Fluororuby; IPS, intraparietal sulcus; IT, inferior temporal cortex; LS, lateral sulcus; LuS, lunate sulcus; MST, medial superior temporal area; MT, middle temporal area; Pul, pulvinar; SC, superior colliculus; d, dorsal; v, ventral.

profundum and stratum album profundum that had not been injected in previous cases. The more medial of these injections included the central gray. Both injections were into the periphery of the visual representation. The more lateral of the two extended from $5^{\circ}$ in the upper field, across the HM, to $60^{\circ}$ in the lower field. The medial injection was confined mostly in the upper field representation, from $10^{\circ}$ to around $40^{\circ}$ of visual space, before crossing into the central gray. Unlike cases 1 and 2, no aspiration of cortex was performed; rather, the syringe was guided through occipital cortex using 
stereotaxic measurements taken from MRI images of the animal made for another study. ${ }^{33}$ Some tracer was deposited in $\mathrm{V} 1$ as the needle was removed. This contamination of visual cortex is likely only enough to reveal local connections, but it cannot be ruled out that some of the FR-filled cells were labeled as a result of the tracer left in V1 rather than of the tracer that was directly injected into the SC.

There were a large number of FR-filled cells within V1. Intrinsic connections that may have been labeled as a result of V1 contamination during the injection could not be distinguished from those resulting from projections to the SC. Outside of V1, however, the pattern of projections was different from that revealed by our more superficial injections in cases 1 and 2. While other early visual areas did contain FR-filled cells, far more were located in parietal cortex. Neurons were labeled on either side of the IPS, though not in the fundus. Unlike our superficial injections, these FR injections led to extensive labeling around the STS. The expansion of label into the regions of the IPS and STS suggest that the intermediate and deep layers of the colliculus receive more input from visuomotor areas in the parietal cortex and multimodal sensory areas around the STS than do the superficial layers. Since we could not determine which FR-backfilled neurons were filled as a result of the injections into the SC and which resulted from tracer contamination in V1, we did not examine the density of projections in this case.

\section{Case I frontal cortex}

The only area outside of the visual cortex and posterior parietal cortex that contained label after injection of tracers into the SC was the FEF of the frontal cortex (Figure 8). Like visual areas of cortex, the visuomotor area FEF is topographically arranged, with central vision being represented laterally and peripheral vision medially. ${ }^{34}$ Both DY and FR injections overlapped in the colliculus, and, as a result, neurons labeled by these injections overlapped in the FEF (Figure 8C and D for DY alone, and E for FR alone). Most of the cells labeled by these injections were concentrated along the arcuate sulcus, lateral to the tip of the principal sulcus. The DY-filled neurons covered a larger extent of the arcuate sulcus, likely due to the larger medial-lateral spread of this injection. The location of the FR- and DY-filled cells appeared to be roughly topographically matched to the retinotopic location of the $\mathrm{SC}$ injections. The widespread FB injection covered the rostral half of the SC, but was too superficial to label many neurons in the FEF. The FB labeled cells resulting from the injection were slightly anterior to cells labeled by the FR and DY injection (Figure 8C), but also centered laterally
(Figure 8F). There were also cells labeled by the FB injection outside of the FEF in the lower bank of the principal sulcus. The widespread FB injection spread into the pretectum and the caudal pulvinar. Labeled neurons in two locations of the lateral prefrontal cortex were likely labeled by the spread of the tracers into the pulvinar. ${ }^{6,31}$ As with visual cortex, the retinotopic location of double-labeled cells roughly matched the location of overlap of the injections (Figure 8G).

\section{Discussion}

Injections of multiple tracers in the superficial layers of the SC of macaques revealed that V1, V2, V3, and MT all project to the superficial three layers of the SC, the SZ, SGS, and SO. When an injection was confined to the superficial layers of the SC, only a small number of filled cells were found in IT, and no labeled neurons were found in the posterior parietal cortex. Outside of the visual cortex, the FEFs also contained cells labeled by injections of tracers in the superficial and upper intermediate layers of the SC. The connections from the visual cortex to the SC appeared to maintain at least a rough retinotopic matching. Those from FEF to SC also appeared to have some topography, though the projections from the FEF may be more loosely arranged than those from the early visual areas. V1 contributed most of the corticotectal projections, with $\mathrm{V} 2$ providing the next highest projection. The magnitude of each visual area's corticotectal projection varied across tracers, most likely reflecting the differences in tracer uptake and the laminar and sublaminar locations of the injection cores. V1 and V2 project the most superficially, with other visual areas projecting deeper in the $\mathrm{SC} .{ }^{11}$

\section{Pattern of corticotectal projections}

The primary source of cortical input to the superficial layers of the SC comes from early visual areas. This result is consistent with the results of earlier studies, based on the smaller, more superficial injections of Lock et al. ${ }^{17}$ Injections of multiple tracers in the superficial layers of the SC in New World monkeys ${ }^{35}$ and prosimian galagos ${ }^{36}$ revealed a pattern of projections coming from areas V1, V2, V3, DM, DL (or V4), and the MT complex. Taking these results as a whole, we conclude that all early visual areas project to the superficial $\mathrm{SC}$ of primates. This pattern of projections is indicated by solid lines in Figure 9.

Only a few cells in the IT cortex were labeled by our injections into the SC; however, a large number of cells in the IT cortex were labeled by injections that involved part of the pulvinar (Figures 5 and 7, gray). In the New World 

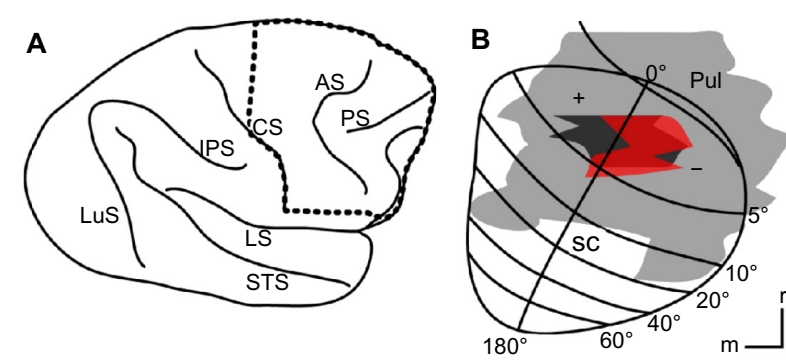

C

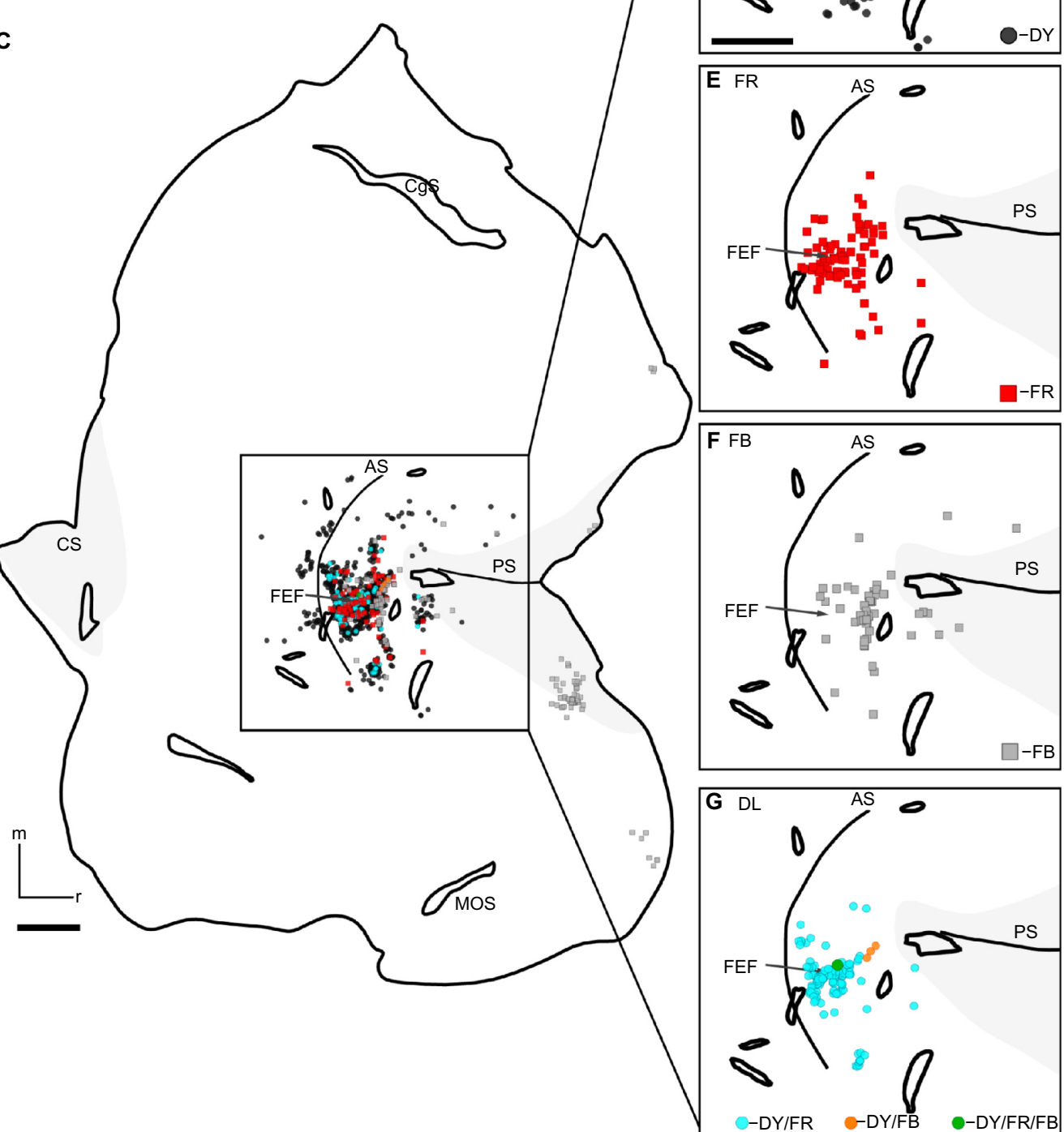

Figure 8 Case I Frontal Cortex.

Notes: (A) Cortical region denoted as frontal cortex in macaques is indicated by dotted line. (B) Top-down view of the reconstructed case I injection sites in the SC. Left is medial, rostral is up. (C) Distribution of cells through the frontal cortex in case I. Areal boundaries were determined from adjacent sections stained for cytochrome oxidase and myelin. The depths of the central and principal sulci are shaded in light gray. (D-F) Closer view of cells labeled by each tracer around the arcuate sulcus. (G) Closer view of double-labeled cells in the boxed region. In cortex, right is rostral, up is medial. Scale bar is $5 \mathrm{~mm}$.

Abbreviations: AS, arcuate sulcus; CgS, cingulate sulcus; CS, central sulcus; DL, dorsolateral area; DY, diamidino yellow; FB, fast blue; FEF, frontal eye field; FR, Fluororuby; IPS, intraparietal sulcus; LS, lateral sulcus; LuS, lunate sulcus; MOS, medial orbital sulcus; PS, principal sulcus; Pul, pulvinar; SC, superior colliculus; STS, superior temporal sulcus.

monkeys ${ }^{35}$ and prosimians, ${ }^{36}$ few neurons in IT were labeled by SC injections. We could not exclude IT cortex as a source of inputs to the superficial SC. Any projection from this region to the upper layers of the SC, however, would be weak. The somewhat uncertain connections between the IT cortex and superficial SC layers is indicated with a dashed line in Figure 9.

Clearly, there were more labeled cells in the cortex surrounding the IPS in cases where an injection was centered in the SGI and SAI of the SC (Figure 7, red). The same 
region of the IPS in macaque monkeys and the comparable part of the posterior parietal cortex of the New World monkeys $^{35}$ and galagos ${ }^{36}$ was labeled when the tracer injection extended, even if only slightly, into the intermediate layers in other studies. The projections of IPS cortex to the intermediate layers of the SC may relate to the role of the $\mathrm{SC}$ in gaze shifts ${ }^{37}$ or defensive movements. ${ }^{4,38}$ Previous anterograde tracer studies in macaques revealed projections from both the FEF and the LIP of the IPS terminate in the intermediate layers of the SC..$^{7,9,39}$ In addition to the LIP region, other regions of cortex around the IPS appear to project to the SC. In our cases, we cannot exclude a possible projection of IPS areas to the superficial SC due to spread of the tracer injections to include the upper part of the intermediate layers of the SC (Figure 9). Further studies of more focused injections will differentiate between these two projections.

Our results also revealed a connection between the frontal cortex and SC (Figure 8); however, in many of our injections, it was quite difficult to tell if the core of tracer uptake extended only into the deepest part of the superficial layers (through SO), or if it crossed into the uppermost part of SGI, the uppermost intermediate layer of the SC. The intermediate $\mathrm{SC}$ in macaques receives projections from the $\mathrm{FEF}^{9,33,39}$ and, although not identified as such, the label around the arcuate sulcus in early macaque studies probably was in the $\mathrm{FEF}{ }^{15}$ and these injections likely included the intermediate layers of the SC. In titi (Callicebus moloch), owl (Aotus trivirgatus), and marmoset (Callithrix jacchus) monkeys, the FEF region was consistently labeled after SC injections that included the uppermost part of the intermediate SC layers. ${ }^{35}$ Evidence for FEF projections to the SC in galagos is less clear; connections from the frontal cortex have been identified, though they do not appear confined to the physiologically defined $\mathrm{FEF}^{36}$ Furthermore, tracer injections placed into the FEF of galagos failed to label terminations in the $\mathrm{SC} .{ }^{40}$ In other primates, FEF projects mainly onto the intermediate layers, though terminals were labeled in SO. ${ }^{31}$ Thus, the cells in FEF that were backfilled by our injections may indicate projections from the FEF to the deepest part of SO, as well as the intermediate layers of the SC, but the lack of DY and FR label around the IPS in case 1 (Figures 3 and 4) suggested that tracer uptake from the intermediate layers was weak. Thus, in Figure 9, we have

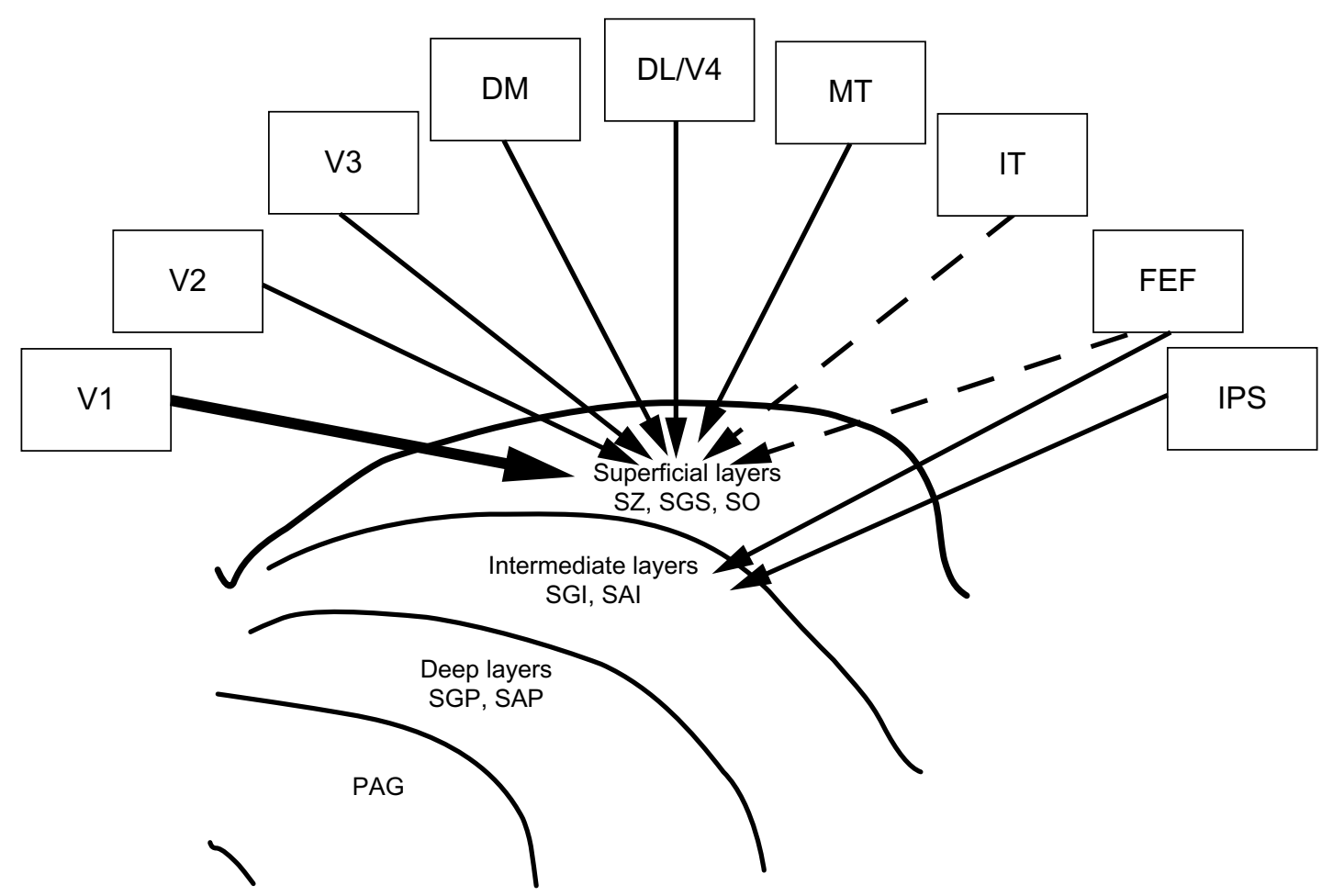

Figure 9 A summary of the projections from cortical areas to the superficial and intermediate layers of the SC.

Notes: In macaques, VI has the densest connections to the superficial SC, but V2, V3, DM, DL/V4, and MT all have significant projections as well. IT has weak connections to the SC, if any. FEF projects to both the superficial and intermediate layers, while areas around the IPS project to the intermediate layers of the SC.

Abbreviations: DL, dorsolateral area; DM, dorsomedial area; FEF, frontal eye field; IPS, intraparietal sulcus; IT, inferior temporal cortex; MT, middle temporal area; PAG, periaqueductal gray; SAI, stratum album intermedium; SAP, stratum album profundum; SGI, stratum griseum intermedium; SGP, stratum griseum profundum; SGS, stratum griseum superficiale; SO, stratum opticum; SZ, stratum zonale; SC, superior colliculus. 
indicated projections from the FEF to both the superficial and intermediate layers of the SC.

As in previous reports on both macaques and New World monkeys, ${ }^{15,17,35}$ no neurons were labeled in the anterior parietal cortex, multimodal areas of the superior temporal cortex, or frontal cortex outside of the FEF after superficial $\mathrm{SC}$ injections.

In summary, all studied primates have projections from the early visual areas to the superficial SC layers. The areas of the posterior parietal cortex that connect to the colliculus project more strongly to the intermediate layers. The FEF projects mainly to the intermediate layers in New and Old World monkeys, but the FEF does not appear to connect to any layer of the $\mathrm{SC}$ in galagos. ${ }^{36,40}$ This suggests a general pattern of projections across primates with specific connections from the FEF to the SC in anthropoid monkeys.

\section{Topography of corticotectal projections}

Since the SC and early visual cortical areas are retinotopically organized, it is not surprising to find that corticotectal projections maintain a rough topography. Our results, however, are the first to reveal this in macaque monkeys by injection of multiple anatomical tracers into a single colliculus. The same procedure has been used in both New World monkeys ${ }^{35}$ and galagos. ${ }^{36}$ In all of these species, projection patterns from early cortical visual areas to the $\mathrm{SC}$ are retinotopically matched. From these results, we can conclude that the retinotopy of the superficial SC is not only the result of the direct retinal inputs, but is also reinforced by cortical inputs.

\section{Magnitude of corticotectal projections}

All early visual areas project to the superficial SC, but their projections were not of the same magnitude. In macaques, $\mathrm{V} 1$ contains the highest percentage of labeled cells as a result of injections into the SZ, SGS, and SO of the SC (Tables 1 and 2). The relative magnitude of the $\mathrm{V} 1$ projection is indicated by line thickness in the summary figure (Figure 9). V1 projections in marmoset and titi monkeys represented about $18 \%-30 \%$ of the total corticotectal projections revealed in each of these species, larger than any other single area. ${ }^{35}$ V1 has similarly strong projections to the superficial SC in prosimian galagos. ${ }^{36}$ The higher magnitude of connections between V1 and the superficial colliculus compared to other cortical areas reflects the large size of $\mathrm{V} 1$ as well as the density of its projecting neurons. A strong projection from V1 suggests that there is a large amount of relatively unprocessed visual information being sent directly to the colliculus, perhaps to influence visuomotor behaviors. Surprisingly, lesioning or inactivating V1 appears to have little effect on neurons in the superficial SC, but disrupts visual responses in deeper layers. ${ }^{41}$

MT also had relatively dense projections to the superficial $\mathrm{SC}$ in comparison to other early visual areas of macaque monkeys (Tables 1 and 2). If all early visual areas project to the colliculus with a similar density, then the number of cells labeled in MT should be considerably lower than those labeled in V1, since V1 contains more neurons and occupies a larger portion of the cortical surface. MT is about $7 \%$ of the size of V1 in macaques, ${ }^{25}$ and, as seen here, about $5 \%$ of the total number of cells labeled by injections into the superficial $\mathrm{SC}$ were found in MT. Thus, the magnitude of the projection from MT to the SC is about what would be expected if projecting neurons were equally distributed in MT and V1. In contrast, the density of MT-projecting neurons was found to be higher than expected in New World monkeys. In all three species of New World monkeys tested, the number of labeled neurons in MT was outmatched only by the magnitudes of V1 and V2 projections. ${ }^{35}$ In New World monkeys, MT is about $10 \%$ the size of $1,{ }^{42,43}$ and, rather than containing about $10 \%$ of labeled cells compared to V1, MT contained about 33\% to $50 \%$ of the number of cells labeled in $\mathrm{V} 1$ after retrograde tracer injections in the SC. ${ }^{35}$ Although projections from MT to the SC terminate somewhat deeper than those from V1, ${ }^{11}$ and injections may not have equally involved both injection zones, this likely means that, in New World monkeys, the density of cells projecting from MT is considerably higher than most other early visual areas because a larger pool of its smaller total number of cells projects to the SC. The reason for this difference is unclear.

In galagos, the magnitude of the MT projection appears very different from that seen in the anthropoid primates. In these prosimians, the majority of inputs from the MT complex to the superficial SC came from the medial superior temporal area and fundus of the superior temporal sulcus, rather than MT itself. ${ }^{36}$ A larger number of backfilled neurons in MT of galagos was found only when the injections included more of the intermediate layers of the SC, and even then the magnitude of these projections remained less than those seen in New World ${ }^{35}$ and Old World monkeys (Tables 1 and 2). Thus, the proportional contribution of cortical projections to the $\mathrm{SC}$ appears to be variable across primate taxa, even though the proportional size of MT to V1 remains about 7\%-10\%. Lesions of MT in macaques reduce or eliminate the responsiveness of SC neurons to motion if a target in the receptive field moves relative to the background. ${ }^{44,45}$ 


\section{Conclusion}

There is a general pattern of projections from the visual cortex to the superficial SC in all primates. While the visual areas projecting to the visual layers of the $\mathrm{SC}$ are similar, there is a variable proportion of projections from MT to the SC across primate taxa. Additionally, the visuomotor area FEF is added to the complement of areas projecting to the deepest part of SO and into the intermediate areas in anthropoid primates. Finally, only injections that include the intermediate and deep layers of the SC result in labeled cells in the cortex around the IPS and STS in all primate species. The cortical inputs to the SC are, of course, important in that they provide visual information that influences the SC outputs to the visual thalamus and pretectum and provide sensory signals that are translated into motor signals that guide eye and head movements so that gaze is directed toward objects of interest. ${ }^{46,47}$

\section{Acknowledgments}

The authors thank Drs Troy Hackett and Jeffrey Schall for animals, Mary Feurtado for surgical assistance, Laura Trice and Mary Varghese for tissue processing, and Dr Christine Collins for suggestions during data analysis. JHK was supported by a NIH grant EY002686.

\section{Author contributions}

Study concept and design: CMC, DCL, and JHK. Acquisition of data: CMC and DCL. Analysis and interpretation of data: PB, CMC, and DCL. Drafting the article or revising it critically for important intellectual content: $\mathrm{PB}, \mathrm{CMC}$, JHK, and DCL. Obtained funding: JHK. All authors had full access to all the data in the study and take responsibility for the integrity of the data and the accuracy of the data analysis.

\section{Disclosure}

The authors report no conflicts of interest in this work.

\section{References}

1. Kaas J, Huerta M. The subcortical visual system of primates. In: Steklis H, editor. Comparative primate biology. New York: Alan R. Liss, Inc; 1988;4:327-391.

2. Munoz DP, Schall JD. Concurrent, distributed control of saccade initiation in the frontal eye field and superior colliculus. In: Hall WC, Moschovakis A, editors. The Superior Colliculus: New Approaches for Studying Sensorimotor Integration. Boca Raton, FL: CRC Press; 2004:55-82.

3. Comoli E, Das Neves Favaro P, Vautrelle N, Leriche M, Overton P, Redgrave P. Segregated anatomical input to sub-regions of the rodent superior colliculus associated with approach and defense. Front Neuroanat. 2012;6:9.
4. DesJardin JT, Holmes AL, Forcelli PA, et al. Defense-like behaviors evoked by pharmacological disinhibition of the superior colliculus in the primate. $J$ Neurosci. 2013;33(1):150-155.

5. Benevento LA, Fallon JH. The ascending projections of the superior colliculus in the rhesus monkey (Macaca mulatta). J Comp Neurol. 1975;160(3):339-361.

6. Harting JK, Huerta MF, Frankfurter AJ, Strominger NL, Royce GJ. Ascending pathways from the monkey superior colliculus: an autoradiographic analysis. J Comp Neurol. 1980;192(4):853-882.

7. Leichnetz GR, Spencer RF, Hardy SG, Astruc J. The prefrontal corticotectal projection in the monkey; an anterograde and retrograde horseradish peroxidase study. Neuroscience. 1981;6(6):1023-1041.

8. Huerta MF, Harting JK. Connectional organization of the superior colliculus. Trends Neurosci. 1984;7(8):286-289.

9. Lynch JC, Graybiel AM, Lobeck LJ. The differential projection of two cytoarchitectonic subregions of the inferior parietal lobule of macaque upon the deep layers of the superior colliculus. J Comp Neurol. $1985 ; 235(2): 241-254$.

10. Kuypers HG, Lawrence DG. Cortical projections to the red nucleus and the brain stem in the Rhesus monkey. Brain Res. 1967;4(2-3): $151-188$.

11. Graham J, Lin CS, Kaas JH. Subcortical projections of six visual cortical areas in the owl monkey, Aotus trivirgatus. J Comp Neurol. 1979;187(3):557-580.

12. Ungerleider LG, Desimone R, Galkin TW, Mishkin M. Subcortical projections of area MT in the macaque. J Comp Neurol. 1984;223(3): 368-386.

13. Künzle H, Akert K, Wurtz RH. Projection of area 8 (frontal eye field) to superior colliculus in the monkey. An autoradiographic study. Brain Res. 1976;117(3):487-492.

14. Abel PL, O'Brien BJ, Lia B, Olavarria JF. Distribution of neurons projecting to the superior colliculus correlates with thick cytochrome oxidase stripes in macaque visual area V2. J Comp Neurol. 1997;377(3): 313-323.

15. Fries W. Cortical projections to the superior colliculus in the macaque monkey: a retrograde study using horseradish peroxidase. J Comp Neurol. 1984;230(1):55-76.

16. Fries W, Distel H. Large layer VI neurons of monkey striate cortex (Meynert cells) project to the superior colliculus. Proc R Soc Lond B Biol Sci. 1983;219(1214):53-59.

17. Lock TM, Baizer JS, Bender DB. Distribution of corticotectal cells in macaque. Exp Brain Res. 2003;151(4):455-470.

18. Lund JS, Lund RD, Hendrickson AE, Bunt AH, Fuchs AF. The origin of efferent pathways from the primary visual cortex, area 17, of the macaque monkey as shown by retrograde transport of horseradish peroxidase. J Comp Neurol. 1975;164(3):287-303.

19. Wong P, Kaas JH. Architectonic subdivisions of neocortex in the Galago (Otolemur garnetti). Anat Rec (Hoboken). 2010;293(6):1033-1069.

20. Lyon DC, Kaas JH. Evidence for a modified V3 with dorsal and ventral halves in macaque monkeys. Neuron. 2002;33(3):453-461.

21. Stepniewska I, Collins CE, Kaas JH. Reappraisal of DL/V4 boundaries based on connectivity patterns of dorsolateral visual cortex in macaques. Cereb Cortex. 2005;15(6):809-822.

22. Gallyas F. Silver staining of myelin by means of physical development. Neurol Res. 1979;1:203-209.

23. Wong-Riley M. Changes in the visual system of monocularly sutured or enucleated cats deomonstrable with cytochrome oxidase histochemistry. Brain Res. 1979;171(1):11-28.

24. Geneser-Jensen FA, Blackstad TW. Distribution of acetyl cholinesterase in the hippocampal region of the guinea pig. I. Entorhinal area, parasubiculum, and presubiculum. Z Zellforsch Mikrosk Anat. 1971;114(4): 460-481.

25. Weller RE, Kaas JH. Retinotopic patterns of connections of area 17 with visual areas V-II and MT in macaque monkeys. J Comp Neurol. $1983 ; 220(3): 253-279$. 
26. Olavarria JF, Van Essen DC. The global pattern of cytochrome oxidase stripes in visual area V2 of the macaque monkey. Cereb Cortex. 1997; 7(5):395-404.

27. Kaas JH, Lyon DC. Pulvinar contribution to the dorsal and ventral streams of visual processing in primates. Brain Res Rev. 2007;55: 285-296.

28. Puigdellívol-Sánchez A, Prats-Galino A, Ruano-Gil D, Molander C. Efficacy of the fluorescent dyes Fast Blue, Fluoro-Gold, and Diamidino Yellow for retrograde tracing to dorsal root ganglia after subcutaneous injection. J Neurosci Methods. 1998;86(1):7-16.

29. Dineen JT, Hendrickson A. Overlap of retinal and prestriate cortical pathways in the primate pretectum. Brain Res. 1983;278(1-2): 250-254.

30. Asanuma C, Andersen RA, Cowan WM. The thalamic relations of the caudal inferior parietal lobule and the lateral prefrontal cortex in monkeys: divergent cortical projections from cell clusters in the medial pulvinar nucleus. J Comp Neurol. 1985;241(3):357-381.

31. Huerta MF, Krubitzer LA, Kaas JH. Frontal eye field as defined by intracortical microstimulation in squirrel monkeys, owl monkeys, and macaque monkeys: I. Subcortical connections. J Comp Neurol. 1986;253(4):415-439.

32. Stepniewska I. The pulvinar complex. In: Kaas JH, Collins CE, editors. The Primate Visual System. Boca Raton, FL: CRC Press; 2003:53-80.

33. Pouget P, Stepniewska I, Crowder EA, et al. Visual and motor connectivity and the distribution of calcium-binding proteins in macaque frontal eye field: implications for saccade target selection. Front Neuroanat. 2009;3:2.

34. Schall JD, Morel A, King DJ, Bullier J. Topography of visual cortex connections with frontal eye field in macaque: convergence and segregation of processing streams. J Neurosci. 1995;15(6): 4464-4487.

35. Collins CE, Lyon DC, Kaas JH. Distribution across cortical areas of neurons projecting to the superior colliculus in new world monkeys. Anat Rec A Discov Mol Cell Evol Biol. 2005;285(1):619-627.
36. Baldwin MK, Kaas JH. Cortical projections to the superior colliculus in prosimian galagos (Otolemur garnetti). J Comp Neurol. 2012;520(9): 2002-2020.

37. Freedman EG, Sparks DL. Activity of cells in the deeper layers of the superior colliculus of the rhesus monkey: evidence for a gaze displacement command. J Neurophysiol. 1997;78(3):1669-1690.

38. Stein BE, Stanford TR, Rowland BA. The neural basis of multisensory integration in the midbrain: Its organization and maturation. Hear Res. 2009;258(1-2):4-15.

39. Künzle H, Akert K. Efferent connections of cortical, area 8 (frontal eye field) in Macaca fascicularis. A reinvestigation using the autoradiographic technique. J Comp Neurol. 1977;173(1):147-164.

40. Stepniewska I, Pouget P, Baldwin M, Kaas J. Cortical and subcortical connections of the frontal eye field in prosimian primates. Program No 263.10/Y27. Neuroscience 2009 Abstracts; October 18, 2009; Chicago, IL. Society for Neuroscience, 2009. Online.

41. Schiller PH, Stryker M, Cynader M, Berman N. Response characteristics of single cells in the monkey superior colliculus following ablation or cooling of visual cortex. J Neurophysiol. 1974;37(1):181-194.

42. Allman JM, Kaas JH. A representation of the visual field in the caudal third of the middle temporal gyrus of the owl monkey (Aotus trivirgatus). Brain Res. 1971;31(1):85-105.

43. Tootell RB, Hamilton SL, Silverman MS. Topography of cytochrome oxidase activity in owl monkey cortex. J Neurosci. 1985;5(10) 2786-2800.

44. Davidson RM, Joly TJ, Bender DB. Effect of corticotectal tract lesions on relative motion selectivity in the monkey superior colliculus. Exp Brain Res. 1992;92(2):246-258.

45. Joly JT, Bender DB. Loss of relative-motion sensitivity in the monkey superior colliculus after lesions of cortical area MT. Exp Brain Res. 1997;117(1):43-58.

46. May PJ. The mammalian superior colliculus: laminar structure and connections. Prog Brain Res. 2006;151:321-378.

47. Isa T, Hall WC. Exploring the superior colliculus in vitro. J Neurophysiol. 2009;102(5):2581-2593.
Eye and Brain

\section{Publish your work in this journal}

Eye and Brain is an international, peer-reviewed, open access journal focusing on clinical and experimental research in the field of neuro-ophthalmology. All aspects of patient care are addressed within the journal as well as basic research. Papers covering original research, basic science, clinical and epidemiological studies, reviews and

\section{Dovepress}

evaluations, guidelines, expert opinion and commentary, case reports and extended reports are welcome. The manuscript management system is completely online and includes a very quick and fair peer-review system, which is all easy to use. Visit http://www.dovepress.com/ testimonials.php to read real quotes from published authors. 